\title{
Dietary Patterns of Young Females and Their Association With Waist Circumference as a Health Index in Northwest of Iran, 2007
}

\author{
Mohammad Alizadeh ${ }^{1}$; Alireza Didarloo ${ }^{2, *}$; Ahmad Esmaillzadeh ${ }^{3}$ \\ ${ }_{1}^{1}$ Food and Beverages Safety Research Center, Department of Nutrition, Faculty of Medicine, Urmia University of Medical Sciences, Urmia, IR Iran \\ ${ }_{2}^{2}$ Social Determinants of Health Research Center, Department of Health and Preventive Medicine, Faculty of Medicine, Urmia University of Medical Sciences, Urmia, IR Iran \\ 3 Food Security Research Center, Isfahan University of Medical Sciences, Isfahan, IR Iran \\ ${ }^{*}$ Corresponding Author: Alireza Didarloo, Social Determinants of Health Research Center, Department of Health and Preventive Medicine, Faculty of Medicine, Urmia University of \\ Medical Sciences, P. O. Box: 57561-15111, Urmia, IR Iran. Tel: +98-4412752372, Fax:+98-4412780800, E-mail: didarloo_a@yahoo.com
}

Received: January 15, 2014; Revised: August 13, 2014; Accepted: November 24, 2014

\begin{abstract}
Background: Despite the higher prevalence of overweight and obesity among young people in western countries, the 50th and 95th percentile ranks for waist circumference in the Iranian young Females are higher than those of the western ones.

Objectives: Identifying major dietary patterns in Iranian young females, which associate with central obesity, can probably explain the difference between Iranian young females' pattern and those of their western peers regarding obesity.

Patients and Methods: In the current cross-sectional study, a total of 257 young females aged 11 - 15 years old from Talaat Intelligent Guidance School, Tabriz, Iran (2007) were selected for the study using non-probability simple sampling method. Then, usual dietary intakes of all subjects were evaluated by a food frequency questionnaire and anthropometric measurements such as weight, height, waist circumference, and Body Mass Index (BMI) using the standard protocols. Data were analyzed by inferential statistics (One-way ANOVA, Tukey test for Post-Hoc Analysis, Chi-square test, age-adjusted means, analysis of covariance with Bonferroni correction, correlation and partial correlation) by SPSS software.

Results: In the current study, six major dietary patterns were extracted using factor analysis method. Before and after controlling the age, subjects in the upper tertile of the Iranian Central Obesity Making Dietary Pattern (rich in cruciferous vegetables, green leafy vegetables, soft drinks, tomatoes, other vegetables and vegetable oils) had larger waist circumference in comparison with the ones in the lower tertile (before controlling for age: $64.2 \pm 9$ vs. $61.6 \pm 7 \mathrm{P}=0.03$; after: $64.5 \pm 0.8$ vs. $61.5 \pm 0.8, \mathrm{P}=0.009$ ). However in lacto vegetarian dietary pattern (rich in legumes, potato, othervegetables, dough, high-fat dairy products and margarine), individuals in the upper tertile had significantly lower weight, waist circumference and body mass index (BMI) in comparison with the ones in the lower tertile (weight: $44.9 \pm 9.3 \mathrm{vs} .51 .4 \pm$ 10.6, P < 0.01; WC: $59.9 \pm 8$ vs. $64 \pm 7.9, \mathrm{P}<0.01$; BMI: $18.6 \pm 3.1$ vs. $20.6 \pm 3.5, \mathrm{P}<0.01)$.

Conclusions: The current study findings suggest that the Iranian Central Obesity Making Dietary Pattern is directly associated with waist circumference (marker of central obesity), while lacto vegetarian dietary pattern is reversely associated with weight, waist circumference and BMI. Special obesity pattern in Iranian young females can be justified by Iranian Central Obesity Making Dietary Pattern".
\end{abstract}

Keywords: Adolescent; Diet; Anthropometry; Iran

\section{Background}

Adolescence is an important period in human life, and nutrition plays the main role in this period. Health problems such obesity could be reduced if healthy nutritional recommendations were practiced in adolescence and continued in adulthood (1). Previous studies regarding adolescent's diet have focused on consumption of nutrients or individual foods. However the use of dietary pattern analysis is necessary to identify the whole diet effects on health outcomes; since this multivariate approach could resolve concerns about potentially antagonistic and interactive effects among nutrients and foods (2). Most previous studies on adult dietary patterns indicated that dietary patterns including fresh fruits and vegetables, legumes, milk, and milk products were associated with lower general and central obesity (3-5). Conversely, dietary patterns containing high fats, oils, sweets, refined meats and red meats were associated with obesity $(6,7)$. To date, few investigations have focused on dietary patterns in adolescents (8). The existing literature highlights that western dietary pattern is associated with greater odds for the overweight and obesity. While the Basic Food dietary pattern rich in standard milk, other milks, breakfast cereal, and white bread had significant negative associations with obesity markers (9-13).

Studies conducted in the US showed that prevalence of high Body Mass Index (BMI) in young female aged 12 - 19 years was $32.6 \%$ (14). In the developing countries the highest prevalence of adolescent overweight was found in Middle East and Eastern Europe. In Iran, from 1993 to 1999, the prevalence of overweight among adolescents doubled and reached $8.3 \%$ (15). High prevalence of overweight and obesity in adolescents of western countries

Copyright (C) 2015, Iranian Red Crescent Medical Journal. This is an open-access article distributed under the terms of the Creative Commons Attribution-NonCommercial 4.0 International License (http://creativecommons.org/licenses/by-nc/4.0/) which permits copy and redistribute the material just in noncommercial usages, provided the original work is properly cited. 
can be related to western dietary pattern. Despite the higher prevalence of overweight and obesity among adolescents in the western countries, the 50th and 95th percentile curves for Waist Circumference (WC) in the Iranian young females are higher than those of the western ones (16). Differences in body fat distribution between young females in the western countries and Iran could be due to genetic or environmental factors such as diet. Identifying major dietary patterns related to central obesity in the Iranian young females can probably explain this different pattern of obesity.

\section{Objectives}

We aimed to identify major dietary patterns related to central obesity in the Iranian young females to explain different pattern of obesity among them.

\section{Patients and Methods}

In the current cross-sectional study, a total of 257 young females aged 11 - 15 years old from Talaat Intelligent Guidance School, Tabriz, Iran (2007) were enrolled in the study using non-probability simple sampling method. Students of this school were representative of all districts of Tabriz. Inclusion criterion for the study was studying in this school, and exclusion criterion was having any chronic disease or special diet in the year prior to the study. Thirteen participants were excluded due to disease or special diets in the year prior to the study and 244 students remained for statistical analysis. Data gathering was performed by a nutritionist after approving the project by the Ethical Committee of the School of Nutrition and Health, Tabriz University of Medical Sciences (approval code: 4.5.8487, approval date: 16 February 2007), and obtaining informed written consent from participants. In the consent form, subjects received information regarding the study, confidentiality of their responses and that the participation was not obligatory. Subjects reported their usual dietary intakes during the previous year via validated 162-item semi quantitative Food Frequency Questionnaire (FFQ) (17). Daily intake of foods was then computed.

Subjects' weight was measured via the Tefal digital scale made in France (with an accuracy of 100 grams). For concise weight measurement, it was necessary to educate clients regarding factors or conditions influencing their weight at the measuring time. The factors included excessive amount of clothing (i.e. overcoats, coats, shoes, etc.) and body movement. Hence it was recommended that weight measurer consider factors or the above mentioned conditions.

Students' height was measured using a tape measure with an accuracy of half a centimeter. The students were asked to take off their shoes and press their legs and heels together touching the wall and stand not to move during measurement. To eliminate the hair thickness, the in- vestigator measured height, by pressing a large triangle lightly on the sagittal plane of the head.

BMI was calculated using the following formula: BMI = (Weight per kg)/ (Height per meter) ${ }^{2}$

Waist Circumference was measured (to the nearest 0.1 $\mathrm{cm}$ ) midway between the lowest ribs and the iliac crest without pressure to the body surface by the light clothing using a tape measure.

Overweight and obesity were determined in accordance with the criteria developed through the US center for health statistics in collaboration with the US Chronic Disease Center (CDC) for prevention and health promotion: subjects with BMI $>85$ th but $\leq 95$ th percentiles were considered overweight and those with BMI $>$ 95th percentile were considered obese. Also overweight and obesity were determined in accordance with the criteria developed through 2000 International Obesity Task Force (IOTF): subjects with BMI $\geq$ BMI-for-age cut-point derived from BMI-age curves passed BMI of 25 at age 18 were considered overweight and those with BMI $\geq$ BMIfor-age cut points derived from BMI-age curves passed BMI of 30 at age 18 were considered obese.

Detailed information regarding identifying dietary patterns is given elsewhere (18). Briefly, after categorizing 162 food items into 40 food groups, factor analysis with varimax rotation was used to identify dietary patterns. Dietary patterns with Eigen value $>1.5$ were considered as major dietary patterns. The dietary pattern score was computed for each dietary pattern by summing intake of food groups weighted by their factor loadings (19). Each subject received a factor score for each identified dietary pattern. Subjects were categorized based on the tertiles of dietary pattern scores. One-way ANOVA and Tukey test for Post-Hoc analysis were used to compare general characteristics across tertiles. The ANOVA assumptions were checked before analysis: assumption of Independent Observations was imperative due to different individuals in the compared groups. Normality of variables, and variances equality were confirmed by Kolmogorov-Smirnov and Levene's tests, respectively. Chi-square test was used where appropriate. Also, age-adjusted means for anthropometric measures across tertiles were determined, and analysis of covariance with Bonferroni correction was used to compare the means. Correlation between major dietary pattern scores and anthropometric measurements was determined by Pearson correlation coefficient. Partial correlation was used to control the effect of age. SPSS software (version 13; SPSS, Chicago, IL, USA) was used for all the statistical analyses.

\section{Results}

According to factor analysis results, there were six major dietary patterns among the subjects. These dietary patterns explained $39.4 \%$ of the total variances. Adequacy of sample size for factor analysis was confirmed 
by Kaiser-Mayer-Olkin (KMO) index $(\mathrm{KMO}=0.770, \mathrm{P}=$ 0.000 ). Detailed information regarding these six dietary patterns and factor loading matrix is given elsewhere (18). Briefly, these dietary patterns included: a) Western Dietary Pattern (WDP) explained 16.6\% of variances and was characterized by high consumption of pizza, organ meats, fruit juices, sweets , desserts, high fat dairy, poultry, processed meats, fruits, and refined grains; b) Sweet Junk Foods Dietary Pattern (SJFDP) predicted $5.6 \%$ of variances and belonged to adolescents who mostly consumed foods such as dried fruits, jams and honey, sugars and tea; c) Lacto Vegetarian Dietary Pattern (LVDP) explained $4.7 \%$ of variances and implied the pattern with high intake of legumes, potato, other vegetables, dough, high-fat dairy products, and margarine; d) Salty Junk Foods Dietary Pattern (SJFDP) predicted $4.4 \%$ of variances and showed pattern rich in carrots, puffs, potato chips, popcorn, and crackers; e) Iranian Central Obesity Making Dietary Pattern (ICOMDP) explained $4 \%$ of variances and was restricted to subjects who consumed foods like cruciferous vegetables, green leafy vegetables, soft drinks, tomatoes, other vegetables, and vegetable oils; and f) Iranian traditional dietary pattern (ITDP) predicted 3.8\% of variances and was characterized by high intake of hydrogenated fats, garlic, broth, tea, poultry and red meats.

Characteristics of subjects and their dietary intakes by tertiles of pattern scores are outlined in Tables 1 - 3 . Adolescents placed in the upper tertile of WDP were younger and more likely to be in high economic status compared with those in the lowest tertile. Individuals located in the top tertile of LVDP and ICOMDP were younger, too. The heights of the subjects in the upper tertile of LVDP and ITDP were shorter compared with those of the ones in the lowest tertile. Higher intake of energy and protein, and lower intake of carbohydrate were observed among those placed in top tertile of WDP. In contrast, subjects in the top tertile of the SJFDP consumed more carbohydrate and those in the top tertile of the LVDP consumed less calorie. Lower intake of protein and higher intake of fat were observed among the subjects in top tertile of ICOMDP.

Means and age adjusted means of anthropometric measures across tertiles of dietary pattern scores are presented in Table 4. Subjects of the top tertile of ICOMDP had higher WC compared with the ones in the lowest tertile $(\mathrm{P}=0.03)$. Adjustment of age increased the positive associations between this dietary pattern and WC $(\mathrm{P}=0.009)$, and also weight $(\mathrm{P}=0.04)$. Compared with subjects of the lowest tertile, those in the upper tertile of LVDP had significantly lower weight, WC, and BMI either before or after controlling for age $(\mathrm{P}<0.01)$. Results did not show any significant association between other dietary patterns and anthropometric measurements ( $P$ $>0.05$ ).

Correlation coefficient between dietary pattern scores and anthropometric measurements before and after con- trolling for age is outlined in Table 5. ICOMDP had marginally direct correlation with WC before controlling for age $(P=0.06)$. This dietary pattern had significantly direct correlation with weight $(\mathrm{P}=0.04)$ and $\mathrm{WC}(\mathrm{P}=0.03)$ and marginally direct correlation with $\mathrm{BMI}(\mathrm{P}=0.05)$ after controlling for age. Results showed an inverse correlation between LVDP scores and all of the anthropometric measurements, and between Iranian traditional dietary pattern scores and only weight either before or after controlling for age.

\begin{tabular}{lcc}
\hline \multicolumn{1}{l}{ Table 1. Characteristics of Study Subjects ${ }^{\mathrm{a}}$} & \\
\hline Parameter & Mean \pm SD & Frequency, \% \\
\hline Age, $\mathbf{y}$ & & \\
\hline 11 & $13.21 \pm 0.97$ & $3(1.2)$ \\
\hline 12 & & $65(25.3)$ \\
\hline 13 & $90(35)$ \\
\hline 14 & & $74(28.8)$ \\
\hline 15 & & $25(9.7)$ \\
\hline Weight, kg & $48.7 \pm 10.4$ & \\
\hline Height, cm & $156.7 \pm 6.7$ & \\
\hline WC, cm & $62.3 \pm 7.9$ & \\
\hline BMI, kg/m & & \\
\hline $\begin{array}{l}\text { Weight categorization } \\
\text { according to CDC }\end{array}$ & $19.7 \pm 3.4$ \\
\hline
\end{tabular}

\begin{tabular}{|c|c|}
\hline Weight $\leq 85$ th percentile & $212(82.5)$ \\
\hline $\begin{array}{l}\text { 85th }<\text { weight } \leq 95 \text { th } \\
\text { percentile }\end{array}$ & $34(13.2)$ \\
\hline Weight $>$ 95th percentile & $11(4.3)$ \\
\hline
\end{tabular}

\section{Weight categorization} according to IOTF

\begin{tabular}{|lc|}
\hline Normal weight & $212(82.5)$ \\
\hline Overweight & $40(15.6)$ \\
Obese & $5(1.9)$ \\
\hline
\end{tabular}

\section{Family economic status}

\begin{tabular}{lc} 
High & $61(23.7)$ \\
Medium & $103(40.1)$ \\
Low & $93(36.2)$ \\
\hline
\end{tabular}

\footnotetext{
a Abbreviations: BMI, Body Mass Index; CDC, the US center for health statistics in collaboration with the US center for chronic disease prevention and health promotion; IOTF, international obesity task force; and WC, waist circumference.
} 
Alizadeh Met al.

\begin{tabular}{|c|c|c|c|c|c|c|c|c|c|c|c|c|}
\hline \multirow[t]{2}{*}{ Parameter } & \multicolumn{3}{|c|}{ Tertiles of WDP Score } & \multirow[t]{2}{*}{ PValue $^{b}$} & \multicolumn{3}{|c|}{ Tertiles of SJFDP Score } & \multirow[t]{2}{*}{ PValue $^{b}$} & \multicolumn{3}{|c|}{ Tertiles of LVDP Score } & \multirow[t]{2}{*}{ PValue $^{\mathrm{b}}$} \\
\hline & $1^{\mathrm{C}}$ & 2 & $3^{d}$ & & $1^{\mathrm{C}}$ & 2 & $3^{d}$ & & $1^{\mathrm{C}}$ & 2 & $3^{d}$ & \\
\hline Sample size & 81 & 81 & 82 & & 81 & 81 & 82 & & 81 & 81 & 82 & \\
\hline Age, $y^{e}$ & $13.5 \pm 0.1$ & $13.2 \pm 0.1$ & $13 \pm 0.1$ & $0.004^{f}$ & $13.2 \pm 0.1$ & $13.3 \pm 0.1$ & $13.1 \pm 0.1$ & 0.2 & $13.5 \pm 0.1$ & $13.3 \pm 0.1$ & $12.9 \pm 0.1$ & $0.000^{\mathrm{g}}$ \\
\hline $\mathrm{Ht}, \mathrm{cm}$ & $157 \pm 0.7$ & $157 \pm 0.7$ & $157 \pm 0.7$ & 0.95 & $156 \pm 0.8$ & $157 \pm 0.7$ & $157 \pm 0.7$ & 0.4 & $157 \pm 0.7$ & $157 \pm 0.6$ & $155 \pm 0.8$ & $0.02^{h}$ \\
\hline High economic status, \% & 18.6 & 24.4 & 28.2 & 0.02 & 23.2 & 25.6 & 22.3 & 0.2 & 20.1 & 25.6 & 24.7 & 0.1 \\
\hline Low economic status, \% & 43 & 30.1 & 26.9 & 0.02 & 42.9 & 33.7 & 32.9 & 0.2 & 44.2 & 36 & 28.2 & 0.1 \\
\hline Overweight by CDC, \% & 16.3 & 10.5 & 12.9 & 0.4 & 13.9 & 17.4 & 8.1 & 0.3 & 13.9 & 11.6 & 14.1 & 0.3 \\
\hline Overweight by IOTF, \% & 18.6 & 15.1 & 12.9 & 0.3 & 15.1 & 22.1 & 9.4 & 0.3 & 17.4 & 15.1 & 14.1 & 0.9 \\
\hline Obesity by CDC, \% & 4.6 & 5.8 & 2.3 & 0.4 & 2.3 & 5.8 & 4.7 & 0.3 & 5.8 & 4.6 & 2.3 & 0.3 \\
\hline Obese by IOTF, \% & 2.3 & 1.2 & 2.3 & 0.3 & 1.2 & 1.2 & 3.5 & 0.3 & 2.3 & 1.2 & 2.3 & 0.9 \\
\hline OAO by CDC, \% & 20.9 & 16.3 & 15.2 & 0.3 & 16.2 & 23.2 & 12.8 & 0.3 & 19.7 & 16.2 & 16.4 & 0.3 \\
\hline OAO by IOTF, \% & 20.9 & 16.3 & 15.2 & 0.3 & 16.3 & 23.2 & 13.2 & 0.3 & 19.7 & 16.3 & 16.4 & 0.9 \\
\hline Calories intake (Kcal/d) & $2447 \pm 88$ & $2512 \pm 83$ & $2591 \pm 55$ & 0.04 & $2490 \pm 105$ & $2613 \pm 110$ & $2445 \pm 90$ & 0.2 & $2661 \pm 97$ & $2476 \pm 83$ & $2411 \pm 69$ & 0.04 \\
\hline $\begin{array}{l}\text { Carbohydrate, \% of total } \\
\text { energy }\end{array}$ & $59.9 \pm 1$ & $59.1 \pm 1.2$ & $58.3 \pm 1.2$ & 0.04 & $57.5 \pm 1$ & $59.3 \pm 1.2$ & $60.5 \pm 1$ & 0.04 & $59.1 \pm 1$ & $58.5 \pm 1.1$ & $59.6 \pm 1$ & 0.8 \\
\hline $\begin{array}{l}\text { Protein, \% of total } \\
\text { energy }\end{array}$ & $11.8 \pm 0.5$ & $12.4 \pm 0.4$ & $13 \pm 0.5$ & 0.007 & $13.6 \pm 0.3$ & $11.7 \pm 4.0$ & $12 \pm 0.4$ & 0.4 & $12.4 \pm 0.5$ & $12.9 \pm 0.3$ & $12 \pm 0.3$ & 0.7 \\
\hline Fat, \% of total energy & $28.3 \pm 0.8$ & $28.5 \pm 0.7$ & $28.7 \pm 0.8$ & $3 \quad 0.09$ & $28.9 \pm 0.6$ & $29.6 \pm 0.6$ & $27.5 \pm 0.6$ & 0.3 & 28.5 & 28.6 & 28.4 & 0.7 \\
\hline $\begin{array}{l}\text { a Abbreviations: LVDP, Lact } \\
\text { b From ANOVA for quantit } \\
\text { c Lowest tertaile. } \\
\text { d Highest tertile. } \\
\text { e Data are presented as me } \\
\text { f Significant difference bet } \\
\text { g Significant difference be } \\
\text { h Significant difference be }\end{array}$ & $\begin{array}{l}\text { to Vegetari } \\
\text { tative varia } \\
\text { ean } \pm \text { Stand } \\
\text { tween terti } \\
\text { tween tert }\end{array}$ & $\begin{array}{l}\text { ian Dietary } \\
\text { ables and c } \\
\text { dard Errors } \\
\text { iles } 1 \text { and } 3\end{array}$ & $\begin{array}{l}\text { y Pattern; } S \\
\text { hi-square } \\
\text { s. } \\
\text { by Tukey p } \\
\text { by Tukey }\end{array}$ & $\begin{array}{l}\text { SJFDP, Swee } \\
\text { for qualita }\end{array}$ & $\begin{array}{l}\text { t Junk Food } \\
\text { tive variable }\end{array}$ & $\begin{array}{l}\text { Is Dietary P } \\
\text { es. }\end{array}$ & Pattern;an & d WDP, Wes & stern Dieta & ry Pattern. & & \\
\hline
\end{tabular}

\begin{tabular}{|c|c|c|c|c|c|c|c|c|c|c|c|c|}
\hline \multirow[t]{2}{*}{ Parameter } & \multicolumn{3}{|c|}{ Tertiles of SJFDP Score } & \multirow[t]{2}{*}{ P Value $^{\mathrm{b}}$} & \multicolumn{3}{|c|}{ Tertiles of ICOMDP Score } & \multirow[t]{2}{*}{ PValue $^{\text {b }}$} & \multicolumn{3}{|c|}{ Tertiles of ITDP Score } & \multirow[t]{2}{*}{ PValue $^{\mathrm{b}}$} \\
\hline & $1^{\mathrm{C}}$ & 2 & $3^{d}$ & & $1^{\mathrm{C}}$ & 2 & $3^{d}$ & & $1^{\mathrm{C}}$ & 2 & $3^{d}$ & \\
\hline Sample size & 81 & 81 & 82 & & 81 & 81 & 82 & & 81 & 81 & 82 & \\
\hline Age, $y^{e}$ & $13.4 \pm 0.1$ & $13.2 \pm 0.1$ & $13.1 \pm 0.1$ & 0.1 & $13.4 \pm 0.1$ & $13.3 \pm 0.1$ & $12.9 \pm 0.1$ & $0.001^{\mathrm{f}}$ & $13.2 \pm 0.1$ & $13.2 \pm 0.1$ & $13.2 \pm 0.1$ & 0.9 \\
\hline Ht & $157 \pm 0.8$ & $157 \pm 0.6$ & $156 \pm 0.8$ & 0.3 & $157 \pm 0.8$ & $158 \pm 0.6$ & $155 \pm 0.7$ & 0.057 & $157 \pm 0.7$ & $157 \pm 0.6$ & $155 \pm 0.8$ & $0.02 \mathrm{~g}$ \\
\hline $\begin{array}{l}\text { High economic } \\
\text { status, \% }\end{array}$ & 23.2 & 20.9 & 27.1 & 0.3 & 20.9 & 29.1 & 21.2 & 0.3 & 30.2 & 16.6 & 22.3 & 0.5 \\
\hline $\begin{array}{l}\text { Low economic } \\
\text { status, \% }\end{array}$ & 45.3 & 25.6 & 37.6 & 0.3 & 41.9 & 36 & 30.6 & 0.3 & 33.7 & 41.9 & 32.9 & 0.5 \\
\hline $\begin{array}{l}\text { Overweight by } \\
\text { CDC,\% }\end{array}$ & 18.6 & 9.3 & 11.8 & 0.6 & 15.1 & 10.5 & 14.1 & 0.6 & 16.3 & 15.1 & 8.2 & 0.2 \\
\hline $\begin{array}{l}\text { Overweight by } \\
\text { IOTF, \% }\end{array}$ & 19.8 & 12.8 & 14.1 & 0.4 & 16.3 & 13.9 & 16.5 & 0.7 & 19.8 & 15.1 & 11.6 & 0.1 \\
\hline Obesity by CDC, \% & 3.5 & 4.6 & 4.7 & 0.6 & 2.3 & 5.8 & 4.7 & 0.6 & 5.8 & 2.3 & 4.6 & 0.2 \\
\hline Obese by IOTF, \% & 2.3 & 1.2 & 2.3 & 0.4 & 1.2 & 2.3 & 2.3 & 0.7 & 2.3 & 2.3 & 1.2 & 0.1 \\
\hline OAO by CDC, \% & 22.1 & 13.9 & 16.5 & 0.6 & 17.4 & 16.3 & 18.8 & 0.6 & 22.1 & 17.4 & 12.8 & 0.2 \\
\hline OAO by IOTF, \% & 22.1 & 14 & 16.4 & 0.4 & 17.5 & 16.2 & 18.8 & 0.7 & 22.1 & 17.4 & 12.8 & 0.1 \\
\hline $\begin{array}{l}\text { Calories intake } \\
\text { (Kcal/d) }\end{array}$ & $2512 \pm 58$ & $2499 \pm 33$ & $2537 \pm 28$ & 0.4 & $2586 \pm 110$ & $2397 \pm 110$ & $2565 \pm 76$ & 0.4 & $2573 \pm 116$ & $2519 \pm 85$ & $2465 \pm 116$ & 0.1 \\
\hline $\begin{array}{l}\text { Carbohydrate, \% } \\
\text { of total energy }\end{array}$ & $59 \pm 1$ & $58.7 \pm 1$ & $59.6 \pm 1.2$ & 0.5 & $59.6 \pm 1$ & $58.4 \pm 1$ & $59.3 \pm 1.1$ & 0.3 & 58.9 & 59.2 & 59.2 & 0.4 \\
\hline $\begin{array}{l}\text { Protein, \% of total } \\
\text { energy }\end{array}$ & $12.7 \pm 0.4$ & $13.2 \pm 0.5$ & $11.4 \pm 0.4$ & 0.4 & $14.9 \pm 0.3$ & $12.1 \pm 0.4$ & $10.3 \pm 0.3$ & 0.007 & $12.7 \pm 0.4$ & $12.6 \pm 0.4$ & $12 \pm 0.3$ & 0.7 \\
\hline $\begin{array}{l}\text { Fat, \% of total } \\
\text { energy }\end{array}$ & $28.3 \pm 0.7$ & $28.1 \pm 0.6$ & $29 \pm 0.6$ & 0.4 & $25.5 \pm 0.9$ & $29.5 \pm 0.9$ & $30.4 \pm 0.8$ & 0.006 & 28.4 & 28.2 & 28.8 & 0.7 \\
\hline \multicolumn{13}{|c|}{$\begin{array}{l}\text { a Abbreviations: ITDP, Iranian Traditional Dietary Pattern; ICOMDP, Iranian Central Obesity Making Dietary Pattern; and SJFDP, Salty Junk Foods Dietary } \\
\text { Pattern. }\end{array}$} \\
\hline
\end{tabular}


Alizadeh Met al.

Table 4. Means and Age Adjusted Means of Anthropometric Measures Across Tertiles of Dietary Pattern Scores ${ }^{\text {a }}$

\begin{tabular}{|c|c|c|c|c|c|c|}
\hline \multirow[t]{2}{*}{ Tertiles } & \multicolumn{3}{|c|}{ Crude Values $^{\text {b }}$} & \multicolumn{3}{|c|}{ Age-Adjusted Values $^{\mathrm{C}}$} \\
\hline & Weight, kg & $\mathrm{WC}, \mathrm{cm}$ & BMI, $\mathrm{kg} / \mathrm{m}^{2}$ & Weight, kg & $\mathrm{WC}, \mathrm{cm}$ & BMI, $\mathrm{kg} / \mathrm{m}^{2}$ \\
\hline \multicolumn{7}{|c|}{ Tertiles of 1st DP score } \\
\hline 1 & $49.3 \pm 10.5$ & $62.3 \pm 7.5$ & $20.0 \pm 3.7$ & $48.8 \pm 1.1$ & $62.2 \pm 0.8$ & $19.9 \pm 0.3$ \\
\hline 2 & $48.4 \pm 10.8$ & $61.9 \pm 8.4$ & $19.4 \pm 3.3$ & $48.2 \pm 1.1$ & $61.9 \pm 0.8$ & $19.3 \pm 0.3$ \\
\hline 3 & $48.8 \pm 10.0$ & $62.5 \pm 7.8$ & $19.8 \pm 3.1$ & $49.5 \pm 1.1$ & $62.7 \pm 0.8$ & $19.9 \pm 0.3$ \\
\hline$P$ value for trend & 0.73 & 0.87 & 0.69 & 0.73 & 0.79 & 0.43 \\
\hline \multicolumn{7}{|c|}{ Tertiles of 2nd DP score } \\
\hline 1 & $48.8 \pm 11.6$ & $62.5 \pm 8.8$ & $19.9 \pm 3.6$ & $49.4 \pm 1.1$ & $62.7 \pm 0.8$ & $20.0 \pm 0.3$ \\
\hline 2 & $50.1 \pm 10.3$ & $62.7 \pm 7.1$ & $20.0 \pm 3.2$ & $49.4 \pm 1.1$ & $62.5 \pm 0.8$ & $19.9 \pm 0.3$ \\
\hline 3 & $47.6 \pm 9.1$ & $61.6 \pm 7.7$ & $19.3 \pm 3.2$ & $47.7 \pm 1.1$ & $61.6 \pm 0.8$ & $19.3 \pm 0.3$ \\
\hline$P$ value for trend & 0.44 & 0.44 & 0.22 & 0.44 & 0.64 & 0.32 \\
\hline \multicolumn{7}{|c|}{ Tertiles of 3rd DP score } \\
\hline 1 & $51.4 \pm 10.6$ & $64.0 \pm 7.9$ & $20.6 \pm 3.5$ & $51.2 \pm 1.0$ & $63.9 \pm 0.8$ & $20.5 \pm 0.3$ \\
\hline 2 & $50.1 \pm 10.2$ & $62.9 \pm 7.2$ & $20.0 \pm 3.2$ & $49.9 \pm 1.0$ & $62.9 \pm 0.8$ & $20.0 \pm 0.3$ \\
\hline 3 & $44.9 \pm 9.3$ & $59.9 \pm 8.0$ & $18.6 \pm 3.1$ & $45.4 \pm 1.1$ & $60.0 \pm 0.8$ & $18.7 \pm 0.3$ \\
\hline$P$ value for trend & $<0.01$ & $<0.01$ & $<0.01$ & 0.001 & 0.005 & 0.001 \\
\hline \multicolumn{7}{|c|}{ Tertiles of 4th DP score } \\
\hline 1 & $49.7 \pm 10.3$ & $63.0 \pm 8.7$ & $20.0 \pm 3.2$ & $49.5 \pm 1.1$ & $62.9 \pm 0.8$ & $20.0 \pm 0.3$ \\
\hline 2 & $48.5 \pm 11.5$ & $62.4 \pm 8.0$ & $19.6 \pm 3.6$ & $48.8 \pm 1.1$ & $62.5 \pm 0.8$ & $19.7 \pm 0.3$ \\
\hline 3 & $48.3 \pm 9.3$ & $61.5 \pm 6.9$ & $19.6 \pm 3.2$ & $48.2 \pm 1.1$ & $61.4 \pm 0.8$ & $19.6 \pm 0.3$ \\
\hline$P$ value for trend & 0.37 & 0.22 & 0.46 & 0.70 & 0.47 & 0.75 \\
\hline \multicolumn{7}{|c|}{ Tertiles of 5th DP score } \\
\hline 1 & $47.7 \pm 10.3$ & $61.6 \pm 7.0$ & $19.4 \pm 3.3$ & $47.6 \pm 1.1$ & $61.5 \pm 0.8$ & $19.4 \pm 0.3$ \\
\hline 2 & $48.4 \pm 10.0$ & $61.0 \pm 7.2$ & $19.5 \pm 3.2$ & $47.8 \pm 1.1$ & $60.8 \pm 0.8$ & $19.3 \pm 0.3$ \\
\hline 3 & $50.4 \pm 10.8$ & $64.2 \pm 9.0$ & $20.3 \pm 3.6$ & $51.1 \pm 1.1$ & $64.5 \pm 0.8$ & $20.4 \pm 0.3$ \\
\hline$P$ value for trend & 0.10 & 0.03 & 0.11 & 0.04 & 0.009 & 0.07 \\
\hline \multicolumn{7}{|c|}{ Tertiles of 6th DP score } \\
\hline 1 & $49.7 \pm 10.0$ & $62.4 \pm 7.7$ & $20.0 \pm 3.4$ & $49.7 \pm 1.1$ & $62.4 \pm 0.8$ & $20.0 \pm 0.3$ \\
\hline 2 & $49.6 \pm 11.2$ & $62.8 \pm 8.0$ & $19.9 \pm 3.5$ & $49.7 \pm 1.1$ & $62.8 \pm 0.8$ & $20.0 \pm 0.3$ \\
\hline 3 & $47.2 \pm 9.8$ & $61.6 \pm 8.0$ & $19.3 \pm 3.2$ & $47.1 \pm 1.1$ & $61.6 \pm 0.8$ & $19.3 \pm 0.3$ \\
\hline$P$ value for trend & 0.11 & 0.49 & 0.19 & 0.17 & 0.58 & 0.32 \\
\hline
\end{tabular}

a Abbreviations: WC, Waist Circumference; BMI, Body Mass Index; and DP, Dietary Pattern.

b Crude values are presented as Means \pm Standard Deviations.

${ }^{\mathrm{C}}$ Age-adjusted values are presented as Means \pm Standard Errors.

\begin{tabular}{|c|c|c|c|c|c|c|c|c|c|c|c|c|}
\hline \multirow[t]{3}{*}{ Scores Type } & \multicolumn{6}{|c|}{ Crude } & \multicolumn{6}{|c|}{ Age-Adjusted } \\
\hline & \multicolumn{2}{|c|}{ Weight } & \multicolumn{2}{|c|}{ WC } & \multicolumn{2}{|c|}{ BMI } & \multicolumn{2}{|c|}{ Weight } & \multicolumn{2}{|c|}{ WC } & \multicolumn{2}{|c|}{ BMI } \\
\hline & $\mathbf{r}$ & $\mathbf{p}$ & $\mathbf{r}$ & $\mathbf{p}$ & $\mathbf{r}$ & $\mathbf{p}$ & $\mathbf{r}$ & $\mathbf{p}$ & $\mathbf{r}$ & $\mathbf{p}$ & $\mathbf{r}$ & $\mathbf{p}$ \\
\hline 1st DP score & 0.01 & 0.78 & 0.03 & 0.63 & 0.03 & 0.59 & 0.07 & 0.21 & 0.05 & 0.42 & 0.07 & 0.26 \\
\hline 2nd DP score & -0.02 & 0.67 & -0.01 & 0.82 & -0.04 & 0.48 & -0.03 & 0.63 & -0.01 & 0.81 & -0.04 & 0.46 \\
\hline 3rd DP score & -0.24 & $<0.001$ & -0.20 & 0.001 & -0.23 & $<0.001$ & -0.22 & $<0.001$ & -0.19 & 0.002 & -0.22 & $<0.001$ \\
\hline 4th DP score & -0.001 & 0.88 & -0.04 & 0.45 & 0.007 & 0.91 & -0.001 & 0.98 & -0.04 & 0.47 & 0.01 & 0.85 \\
\hline 5th DP score & 0.08 & 0.19 & 0.11 & 0.06 & 0.09 & 0.12 & 0.12 & 0.04 & 0.13 & 0.03 & 0.12 & 0.05 \\
\hline 6th DP score & -0.14 & 0.02 & -0.08 & 0.17 & -0.10 & 0.08 & -0.13 & 0.03 & -0.08 & 0.19 & -0.10 & 0.10 \\
\hline
\end{tabular}

a Abbreviations: WC, Waist Circumference; BMI, Body Mass Index; and DP, Dietary Pattern. 


\section{Discussion}

In the current study six major dietary patterns were identified among the Iranian young females: WDP, SJFDP, LVDP, SJFDP, ICOMDP and ITDP. Subjects in the top tertile of ICOMDP score had higher WC compared with the ones in the lowest tertile. This dietary pattern which tends to increase central obesity was an exclusive dietary pattern among the subjects. This pattern had higher loads for vegetables, soft drinks, and vegetable oils. This combination of foods recalls Iranian special meals which vegetables such as zucchini, eggplant, tomato, spinach and local green leafy vegetables are fried with ample amount of oil and consumed with carbonated soft drinks. Also, vegetables such as leek, parsley, coriander, fenugreek, celery, green beans and beans are fried with vegetable oils when used in cooking some popular meals such as ghormehsabzi, khoresht-e-karafs, loobia-polo and baghala-polo. This dietary pattern provided high calories by fats and carbohydrates and very low calories by protein. In consistent with this finding, many previous studies attributed the important role of high protein and low fat diets in reducing central obesity (20-23). Also, this dietary pattern highly loaded with foods containing high amount of goitrogens such as cabbages and turnip. Goitrogens can increase obesity via reducing metabolic rate and basal metabolism. This special dietary pattern probably causes a special obesity pattern, central obesity against general obesity. Few studies focused on dietary patterns among adolescents. The existing literature indicated that following dietary patterns were associated with greater odds for overweight and obesity: 1) Western dietary pattern loading highly with takeaway foods, confectionary, red meat, refined grains, processed meats, fried potato, crisps and soft drinks $(9,10,13) .2)$ Health threatening foods dietary pattern containing high sweets, chocolate confectionery, potato crisps, hot chips/fries, artificiallysweetened soft drinks, and sugar-sweetened soft-drinks (11). 3) Modern diet pattern loading highly with white bread, dairy products, sugars, added fats and fruits and decreasing consumption of oils, grains, legumes and vegetables (12). Regarding the special pattern of Iranian adolescents' obesity in comparison with those of the other countries, different obesity-making dietary patterns in this study are not wonderful.

In the current study, subjects of the upper tertile of LVDP had significantly lower weight, WC, and BMI compared with those of the ones in the lowest tertile. In previous studies dietary patterns which had significant negative associations with general and central obesity in adolescents were: 1) Korean traditional dietary pattern recognized with the highest consumption of rice and kimchi, fish and seaweed, and legumes (10),2) Basic Foods dietary pattern loaded highly with standard milk, other milks, breakfast cereal, and white bread (11),3) Fruits and Vegetables' pattern loaded highly with fruit, vegetables, cheese, and brown/multigrain bread (11). The similarity of weight reducing dietary patterns in the current study and two other ones from three previous studies was the lacto vegetarian nature of these dietary patterns. In the third previous study Basic Foods dietary patterns was a dietary pattern highly loaded with plant foods and sea foods and these sea-food-vegetarian dietary patterns associated with low weight in adolescents, too. Reverse correlation between LVDP and anthropometric measurements can be explained by low glycemic index $(24,25)$, low energy density $(26,27)$, high fiber (28-30), high protein (20), low fat (20), high short chain fatty acids (31), and low variety of this dietary pattern (32).

The current study showed a reverse correlation between ITDP and weight but not WC and BMI. Significant reverse correlation between this dietary pattern and weight but not BMI was due to low height of adolescents who had high score for this dietary pattern.The current study had some limitations: first, it was a cross sectional study, therefore, causality cannot be inferred. Second, like any other measurement dietary assessments, it may have some inevitable errors. Third, using factor analysis needs several arbitrary decisions (33). Fourth, the study was conducted exclusively on all of the young females in one school. This sampling strategy did not allow generalizing findings to the target population. On the other hand, the same gender and intelligence of subjects controlled some unknown confounders and could be an advantage of the study. Another advantage of the study was its results, which can help the existing knowledge to identify major dietary patterns related to central obesity in the Iranian young females.

In conclusion, the study findings suggest that ICOMDP characterized by high consumption of cruciferous vegetables, green leafy vegetables, soft drinks, tomatoes, other vegetables, and vegetable oils was directly associated with WC (marker of central obesity), while LVDP with high amounts of legumes, potato, other vegetables, dough, high-fat dairy products and margarine was reversely associated with weight, WC and BMI. Special obesity pattern in the Iranian young females can be justified by ICOMDP.

\section{Acknowledgements}

The authors would like to thank Ms. Roghayye Karimi and Ms. Nahid Hajiri for cooperation.

\section{Authors' Contributions}

Study concept and design: Mohammad Alizade and Ahmad Esmaillzadeh; data analysis and interpretation: Mohammad Alizade, Alireza Didarloo and Ahmad Esmaillzadeh; manuscript drafting: Mohammad Alizade; critical revision of the manuscript for important intellectual content: Alireza Didarloo and Ahmad Esmaillzadeh; statistical analysis: Ahmad Esmaillzadeh, Mohammad Alizade and Alireza Didarloo. 


\section{Funding/Support}

This work was supported by the Urmia Universities of Medical Sciences, Urmia, IR Iran and Tabriz Universities of Medical Sciences, Tabriz, IR Iran.

\section{References}

1. Spear BA. Adolescent growth and development. J Am Diet Assoc. 2002;102(3 Suppl):S23-9.

2. Jacobs DRJ, Steffen LM. Nutrients, foods, and dietary patterns as exposures in research: a framework for food synergy. Am J Clin Nutr. 2003;78(3 Suppl):508S-13S.

3. Tucker LA, Tucker JM, Bailey BW, LeCheminant JD. Dietary patterns as predictors of body fat and BMI in women: a factor analytic study. Am J Health Promot. 2015;29(4):e136-46.

4. Vilela AA, Sichieri R, Pereira RA, Cunha DB, Rodrigues PR, Goncalves-Silva RM, et al. Dietary patterns associated with anthropometric indicators of abdominal fat in adults. Cad Saude Publica. 2014;30(3):502-10.

5. Ricci G, Canducci E, Guida A, Frascari A, Rossi A, Bersani G, et al. The gender-related differences of nutrient intakes in a group of Italian obese patients display the ongoing transition from Mediterranean to western dietary patterns. Obes Surg. 2014;24(6):965-7.

6. Liu J, Hickson DA, Musani SK, Talegawkar SA, Carithers TC, Tucker KL, et al. Dietary patterns, abdominal visceral adipose tissue, and cardiometabolic risk factors in African Americans: the Jackson heart study. Obesity (Silver Spring). 2013;21(3):644-51.

7. Esmaillzadeh A, Azadbakht L. Major dietary patterns in relation to general obesity and central adiposity among Iranian women. J Nutr. 2008;138(2):358-63.

8. Newby PK. Examining energy density: comments on diet quality, dietary advice, and the cost of healthful eating. J Am Diet Assoc. 2006;106(8):1166-9.

9. Ambrosini GL, Huang RC, Mori TA, Hands BP, O'Sullivan TA, de Klerk NH, et al. Dietary patterns and markers for the metabolic syndrome in Australian adolescents. Nutr Metab Cardiovasc Dis. 2010;20(4):274-83.

10. Kim JA, Kim SM, Lee JS, Oh HJ, Han JH, Song Y, et al. Dietary patterns and the metabolic syndrome in Korean adolescents: 2001 Korean National Health and Nutrition Survey. Diabetes Care. 2007;30(7):1904-5.

11. Howe AS, Black KE, Wong JE, Parnell WR, Skidmore PM. Dieting status influences associations between dietary patterns and body composition in adolescents: a cross-sectional study. Nutr J.2013;12:51.

12. Aounallah-Skhiri H, Traissac P, El Ati J, Eymard-Duvernay S, Landais E, Achour N, et al. Nutrition transition among adolescents of a south-Mediterranean country: dietary patterns, association with socio-economic factors, overweight and blood pressure. A cross-sectional study in Tunisia. Nutr J. 2011;10:38.

13. Song Y, Park MJ, Paik HY, Joung H. Secular trends in dietary patterns and obesity-related risk factors in Korean adolescents aged 10-19 years. Int J Obes (Lond). 2010;34(1):48-56.

14. Ogden CL, Carroll MD, Kit BK, Flegal KM. Prevalence of obesity and trends in body mass index among US children and adoles- cents, 1999-2010. JAMA. 2012;307(5):483-90

15. Kelishadi R. Childhood overweight, obesity, and the metabolic syndrome in developing countries. Epidemiol Rev. 2007;29:62-76.

16. Kelishadi R, Gouya MM, Ardalan G, Hosseini M, Motaghian M, Delavari A, et al. First reference curves of waist and hip circumferences in an Asian population of youths: CASPIAN study. J Trop Pediatr. 2007;53(3):158-64.

17. Azadbakht L, Mirmiran P, Esmaillzadeh A, Azizi F. Dairy consumption is inversely associated with the prevalence of the metabolic syndrome in Tehranian adults. Am J Clin Nutr. 2005;82(3):523-30.

18. Alizadeh M, Mohtadinia J, Pourghasem-Gargari B, Esmaillzadeh A. Major Dietary Patterns among Female Adolescent Girls of Talaat Intelligent Guidance School, Tabriz, Iran. Iran Red Crescent Med J. 2012;14(7):436-41.

19. Kim JO, Mueller CW. Factor analysis: Statistical methods and practical issues.New York: Sage; 1978.

20. Abete I, Astrup A, Martinez JA, Thorsdottir I, Zulet MA. Obesity and the metabolic syndrome: role of different dietary macronutrient distribution patterns and specific nutritional components on weight loss and maintenance. Nutr Rev. 2010;68(4):214-31.

21. Tang M, Armstrong CL, Leidy HJ, Campbell WW. Normal vs. high-protein weight loss diets in men: effects on body composition and indices of metabolic syndrome. Obesity (Silver Spring). 2013;21(3):E204-10.

22. Te Morenga L, Mann J. The role of high-protein diets in body weight management and health. BrJ Nutr. 2012;108 Suppl 2:S130-8.

23. Clifton P. Effects of a high protein diet on body weight and comorbidities associated with obesity. BrJ Nutr. 2012;108 Suppl 2:S122-9.

24. Spieth LE, Harnish JD, Lenders CM, Raezer LB, Pereira MA, Hangen SJ, et al. A low-glycemic index diet in the treatment of pediatric obesity. Arch Pediatr Adolesc Med. 2000;154(9):947-51.

25. Ludwig DS. Dietary glycemic index and obesity. $J$ Nutr. 2000;130(2S Suppl):280S-3S.

26. Cuco G, Arija V, Marti-Henneberg C, Fernandez-Ballart J. Food and nutritional profile of high energy density consumers in an adult Mediterranean population. EurJ Clin Nutr. 2001;55(3):192-9.

27. Bell EA, Rolls BJ. Energy density of foods affects energy intake across multiple levels of fat content in lean and obese women. Am J Clin Nutr. 2001;73(6):1010-8.

28. Howarth NC, Saltzman E, Roberts SB. Dietary fiber and weight regulation. Nutr Rev. 2001;59(5):129-39.

29. Maskarinec G, Takata Y, Pagano I, Carlin L, Goodman MT, Le Marchand L, et al. Trends and dietary determinants of overweight and obesity in a multiethnic population. Obesity (Silver Spring). 2006;14(4):717-26.

30. Tucker LA, Thomas KS. Increasing total fiber intake reduces risk of weight and fat gains in women. J Nutr. 2009;139(3):576-81.

31. Rolland V, Roseau S, Fromentin G, Nicolaidis S, Tome D, Even PC. Body weight, body composition, and energy metabolism in lean and obese Zucker rats fed soybean oil or butter. Am J Clin Nutr. 2002;75(1):21-30.

32. Sea MM, Woo J, Tong PC, Chow CC, Chan JC. Associations between food variety and body fatness in Hong Kong Chinese adults. J Am Coll Nutr. 2004;23(5):404-13.

33. Martinez ME, Marshall JR, Sechrest L. Invited commentary: Factor analysis and the search for objectivity. Am J Epidemiol. 1998;148(1):17-9. 